3. Стратегия пространственного развития Российской Федерации до 2025 года : утв. распоряжением Правительства Рос. Федерации от 13 февр. 2019 г. № 207-р // Правительство России : офиц. сайт. - Москва, 19992020. - URL: http://government.ru/docs/35733/ (дата обращения: 01.11.2020).

4. Стратегия развития туризма в России до 2035 года : утв. распоряжением Правительства Рос. Федерации от 20 сент. 2019 г. № 2129-p // Правительство России : офиц. сайт. - Москва, 1999-2020. - URL: http://government.ru/docs/37906/ (дата обращения: 30.10.2020).

5. Стратегия устойчивого развития сельских территорий Российской Федерации на период до 2030 года : утв. распоряжением Правительства Рос. Федерации от 2 февр. 2015 г. № 151-р // Правительство России : офиц. сайт. - Москва, 1999-2020. - URL: http://government.ru/docs/16757/ (дата обращения: 01.11.2020).

6. Стратегия действий в интересах граждан старшего поколения в Российской Федерации до 2025 года : утв. распоряжением Правительства Рос. Федерации от 5 февр. 2016 г. № 164-р // Правительство России : офиц. сайт. - Москва, 1999-2020. - URL: http://government.ru/docs/21692/ (дата обращения: 01.11.2020).

Anna S. Frolova, Ph. D. in Pedagogics Altai State Institute of Culture (Barnaul, Russia) rus.librarian@yandex.ru

\title{
PREPARATION OF A SUBSIDY REQUEST FOR A CULTURAL PROJECT: NOVICE GRANT-SEEKERS' TYPICAL MISTAKES
}

\begin{abstract}
The paper briefly reviews various mistakes that are typical for unexperienced government grant-seekers in subsidy requests for execution of socially significant non-profit projects and programs in cultural sector addressed to expert committees of grant competitions. The key points of argument-based denials of subsidies for execution of such projects outlined in critical comments, expert reports and reviews gave for declined requests as well as the author's own remarks are described.

Keywords: institutions of culture, socially significant cultural project, grant support for a cultural project, mistakes in grant proposal, grant proposal, government grant maker (government grant giver), grants competition in culture sphere, government grant in culture sector, project performers team, project budget.
\end{abstract}

УДК 027.1Тургенев(443.611):026.06:027.53(571.150)

DOI: $10.32340 / 2414-9101-2020-4-77-85$

О. А. Трухина

Алтайская краевая универсальная научная библиотека им. В. Я. Шишкова (Барнаул, Россия) ork_akunb@mail.ru

\section{ОДИССЕЯ РУССКОЙ ТУРГЕНЕВСКОЙ БИБЛИОТЕКИ (ПАРИЖ, ФРАНЦИЯ)}

\begin{abstract}
Аннотация. Кратко охарактеризована история создания в 1875 г. по инициативе русского политического деятеля Г. А. Лопатина Русской общественной библиотеки-читальни в г. Париже (Франция), ныне считающейся старейшим русскоязычным книжным собранием, сформированным за пределами исторической России; мемориальная документная коллекция, основу которой составили книги из личной библиотеки писателя, постепенно обрела статус одного из центров культурной жизни первой волны русской революционной эмиграции во Франции. В статье раскрыт состав документного фонда библиотеки по видам изданий, указаны источники его пополнения до конфискации нацистской оккупационной администрацией в 1940 г., изложена история перемещений библиотеки. Представлено общее описание экземпляров книжных и журнальных изданий, ранее принадлежавших Русской общественной библиотеке-читальне им. И. С. Тургенева, ныне находящихся на хранении в фонде Алтайской краевой универсальной научной библиотеки им. В. Я. Шишкова (г. Барнаул, Россия).
\end{abstract}


Ключевые слова: Русская общественная библиотека-читальня им. И. С. Тургенева, Тургеневская библиотека, книжные знаки, экслибрисы, книжные фонды Тургеневской библиотеки, библиотека и архив Российской сочиал-демократической рабочей партии (РСДРП), библиотека ЛавроваГой, Алтайская краевая универсальная научная библиотека им. В. Я. Шишкова.

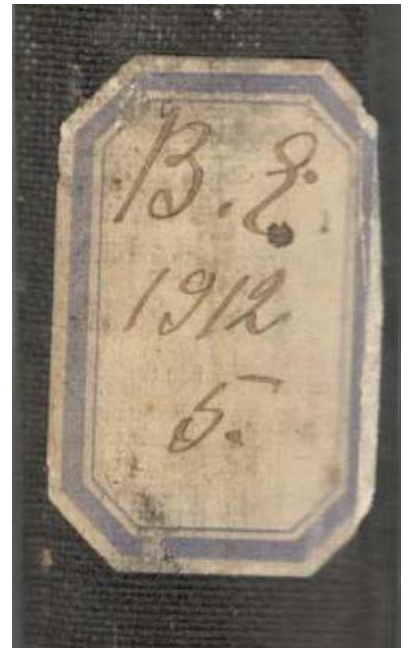

Бумажный ярлык

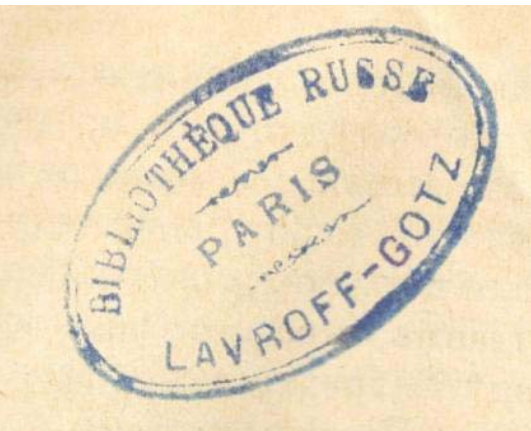

Влад. штемпель библиотеки Лаврова-Гоца

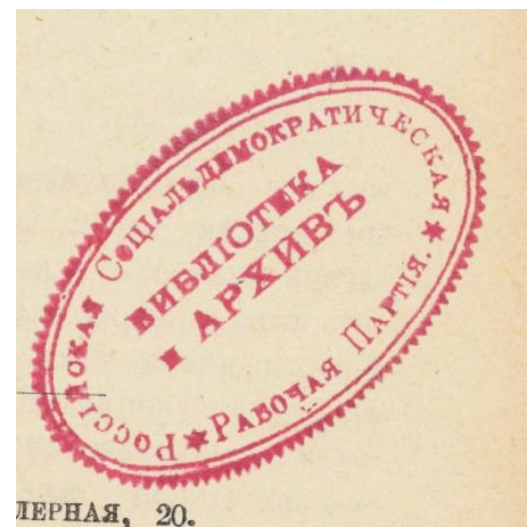

Влад. штемпель библиотеки РСДРП

Среди множества уникальных явлений культуры Русская общественная библиотека имени И. С. Тургенева в Париже занимает исключительное место, более ста лет являясь важнейшим культурным центром русского зарубежья во Франции.

Начиная с 1870-х г. Тургеневская библиотека неоднократно оказывалась на перекрестке всех событий, потрясавших мир, Россию, русскую эмиграцию. Поистине драматической страницей истории библиотеки стала Вторая мировая война. Вихрь огненных лет распылил стотысячное книжное собрание по всему миру. Часть книжной коллекции в результате перемещения культурных ценностей после окончания войны оказалась на территории России. Со временем уцелевшие издания приобрели особую историко-культурную значимость, стали ценным источником для исследователей.

Благодаря владельческим книжным знакам Тургеневской библиотеки удалось выявить в фонде Алтайской краевой универсальной научной библиотеки им. В. Я. Шишкова (далееАКУНБ) и идентифицировать 5 книг и 192 журнала, входивших ранее в состав знаменитого книжного собрания.

Русская Общественная библиотека-читальня была создана в Париже в начале 1875 г. в интересах членов русской колонии, преимущественно состоявшей из политических эмигрантов и учащейся молодежи. Своим рождением она обязана русским студентам, перебравшимся во Францию после того, как царское правительство потребовало от учащихся покинуть Цюрих, слывший рассадником вольнодумства.

Активное участие в делах библиотеки принял Герман Александрович Лопатин (1845-1918)-народник, имя которого наиболее громко звучало в революционном движении 18701880 -х гг. в России. Именно он обратился с просьбой к Ивану Сергеевичу Тургеневу, жившему в то время в Париже, посодействовать в организации библиотеки-читальни для малоимущей части русского Парижа. Знаменитый писатель, который не раз материально помогал соотечественникам, оказавшимся на чужбине, с готовностью откликнулся на эту просьбу. Его книжные пожертвования составили основной фонд библиотеки.

О начальном периоде существования библиотеки сохранились сведения в мемуарах Владимира Францевича ГинтовтДзевалтовского, русского эмигранта, приехавшего в Париж в ноябре 1880 г. В том году библиотека перебралась в новое помещение на улице Бертолет (rue Bertholet, 7). По воспоминаниям В. Ф. Гинтовт-Дзевалтовского, который проработал около года в библиотеке, многие называли ее Тургеневской, а некоторые - эмигрантской. «Библиотека помещалась в трех комнатах. Комната побольше и посветлее именовалась читальней. В ней был широкий, длинный стол, в изобилии покрытый газетами и журналами. Газеты валялись, как попало, а журналы, во избежание их невольных путешествий по Парижу, были привязаны к столу массивными стальными цепочками. Вокруг стола стояло дюжины полторы стульев. Остальные две комнаты занимали стеллажи с книгами. Читальня 


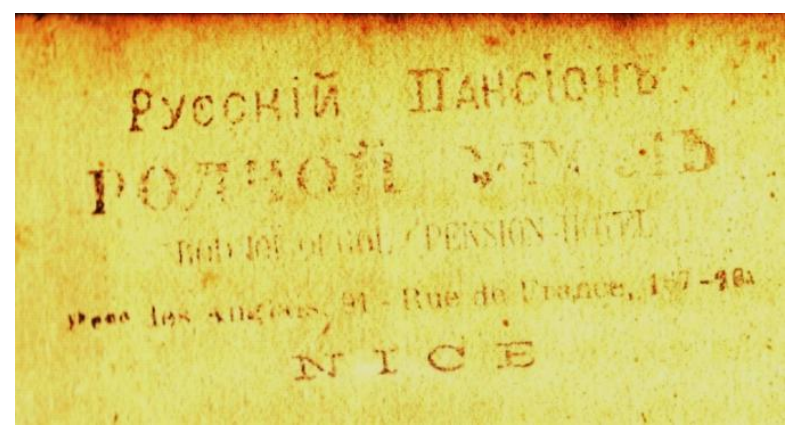

Влад. штемпель Родной угол

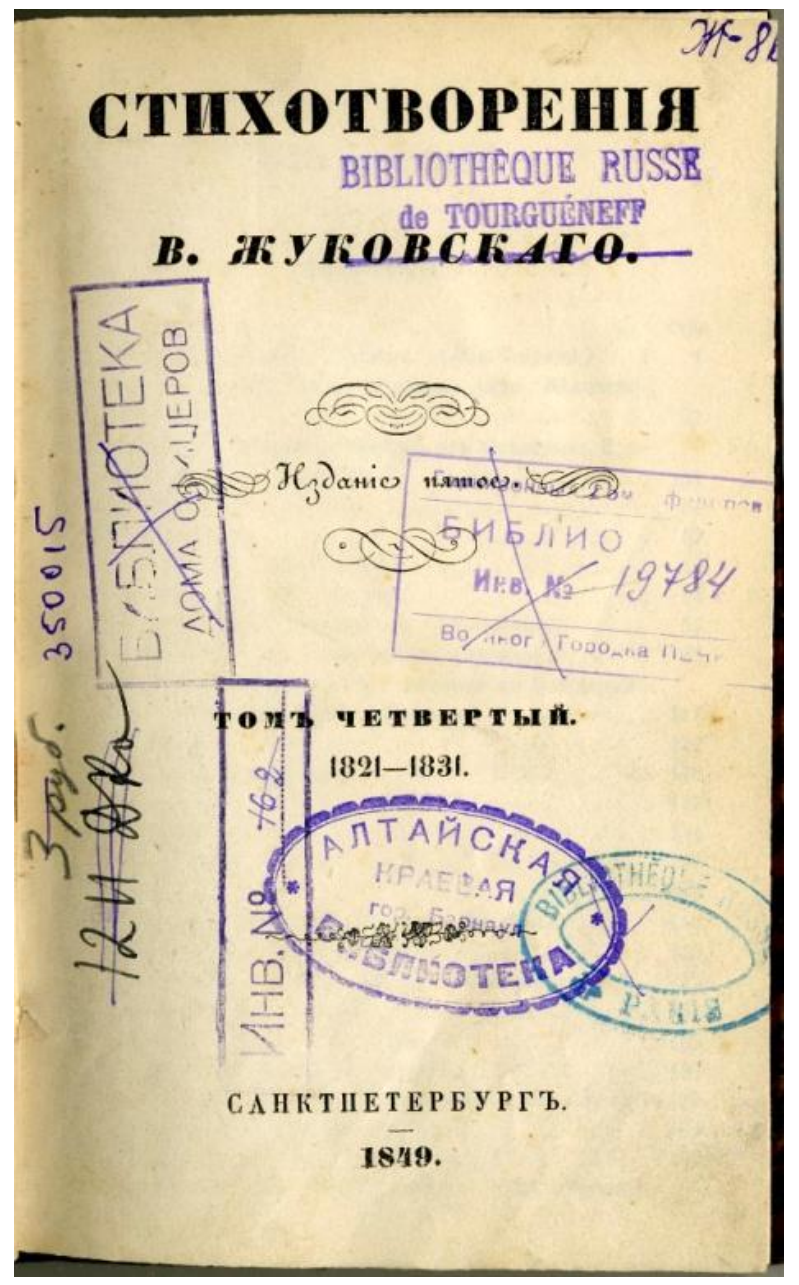

Владельческие знаки

Фонды библиотеки пополнялись за счет покупки книг, даров и интенсивного книгообмена. Сотрудники учреждения собирали весь материал о России, приобретали все иностранные сочинения, посвященные русской тематике. Особенно полно была представлена эмигрантская печать, в частности газеты и журналы, выходившие в Париже на русском языке. Правление библиотеки прилагало все усилия для того, чтобы постоянно поступали новинки беллетристики и фундаментальные пособия по всем отраслям знания, были все толстые журналы. К началу Второй мировой войны собрание периодики насчитывало более 10000 экземпляров журналов и газет [2, с. 134]. Особую ценность представлял журнальный фонд: некоторые из периодических изданий хронологически относились к 1865 г. открывалась с 8-9 часов утра ежедневно, не исключая и всех праздников, закрывалась поздно вечером, с уходом последнего читателя. Библиотека с выдачей книг на дом, для чтения и справок в читальне функционировала с 19 до 22 часов. Кроме этого прямого назначения, библиотека и читальня выполняла и другие функции: частичное собирание кружков, заседаний по вопросам, относящимся и не относящимся к делам библиотеки. Наконец, случалось ей быть и ночлежкой. Один раз в месяц библиотекарь являлся к Тургеневу с докладом о состоянии библиотеки. Так было заведено и исполнялось свято» [1, с. 80$]$.

В 1883 г. библиотека лишилась своего щедрого покровителя. Вполне закономерно, что вскоре после смерти И. С. Тургенева общее собрание членов библиотеки единодушно постановило присвоить ей имя знаменитого писателя. С этого момента был видоизменен и штемпель библиотеки. Рядом с прежним шрифтовым штемпелем на французском языке: «BIBLIOTHÈQUE RUSSE A PARIS» на периодических изданиях стал проставляться круглый штемпель с надписью в рамке: «BIBLIOTHĖQUE RUSSE TOURGUENEFF».

За годы своего существования (1875-1940 гг.) Тургеневская библиотека по разным причинам меняла несколько раз адреса. За ее перемещениями можно проследить по владельческим штемпелям, которые на страницах изданий оставляли оттиск не только названия учреждения, но и новый адрес библиотеки.

Владельческие книжные знаки дают возможность почерпнуть информацию о времени поступления того или иного издания в фонд библиотеки. При просмотре изданий de viso в отделе редких книг АКУНБ выявлено восемь разновидностей шрифтовых штемпелей, два вида экслибриса и три вида суперэкслибриса, указывающие на принадлежность книг и журналов Русской общественной библиотеке им. И. С. Тургенева. 


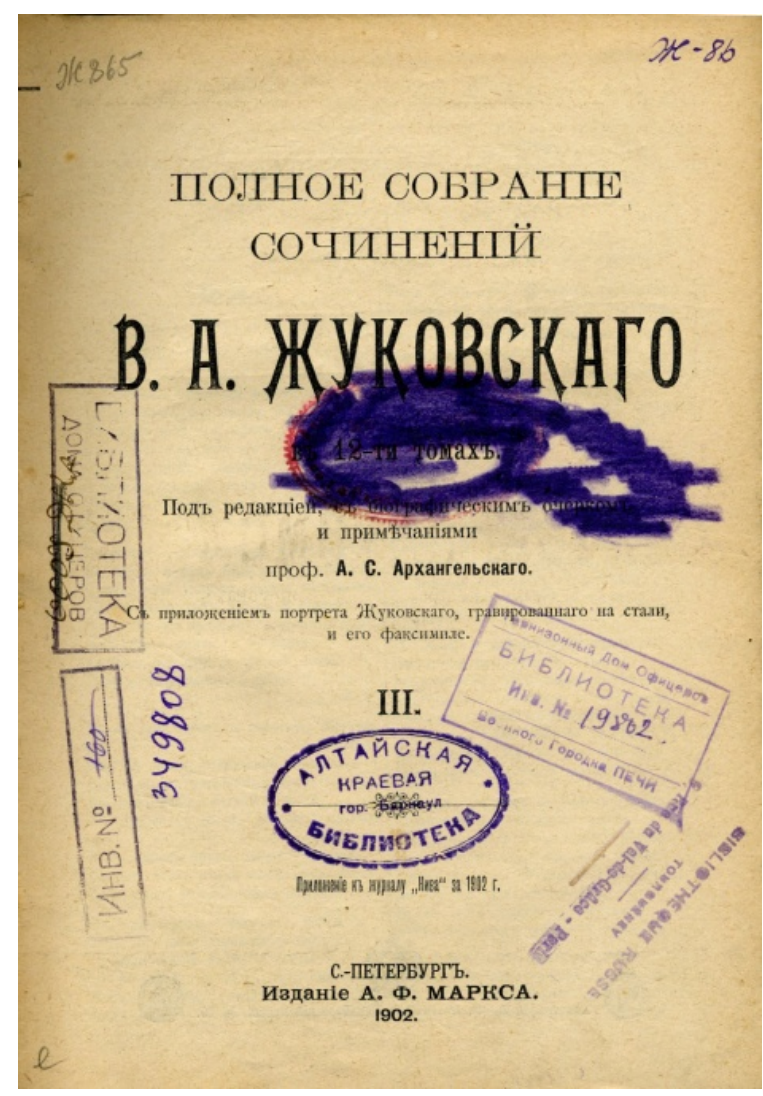

Владельческие знаки 2

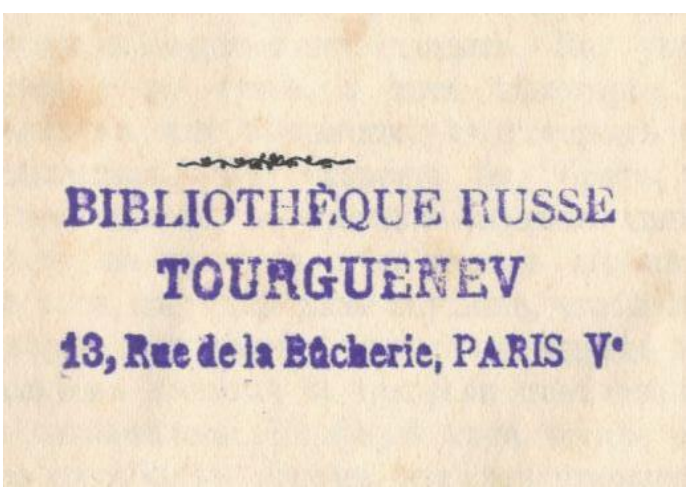

Владельческий штемпель

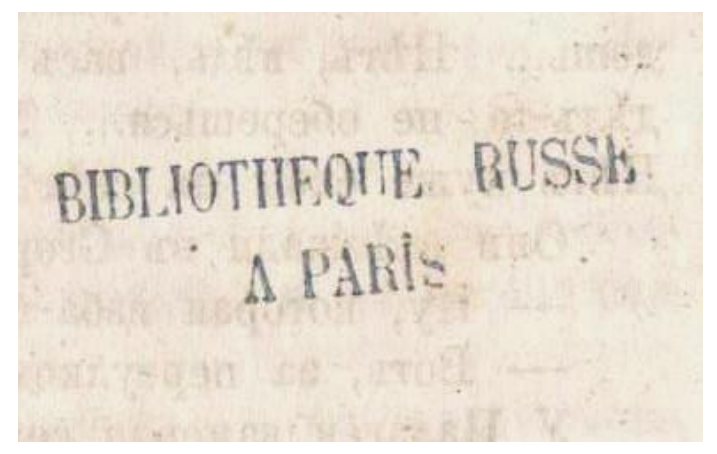

Владельческий штемпель 2
В отделе редких книг АКУНБ хранятся неполные, разрозненные годовые комплекты журналов, имеющие владельческие признаки Тургеневской библиотеки: «Вестник Европы» (122 экземпляра за 1869-1917 гг.), «Былое» (14 экземпляров за 19071909 гг., 1921-1925 гг.), «Вестник археологии и истории» (1 экземпляр за 1885 г.), «Отечественные записки» (53 экземпляра за 1865-1884 гг.), «Исторический вестник» (2 экземпляра за 1910, 1915 гг.). Периодические издания поступили в АКУНБ в 1990 г. из Горно-Алтайского научноисследовательского института истории, языка и литературы.

В начальный период существования Русской общественной библиотеки И. С. Тургенев заботился о том, чтобы читальня обеспечивалась современными журналами. Он неоднократно обращался к издателю журнала «Вестник Европы» М. М. Стасюлевичу с просьбой выслать в Париж свежие номера журнала.

«Вестник Европы» являлся одним из самых влиятельных российских либеральных журналов второй половины XIX - начала XX вв. Сохранившиеся отдельные номера журнала «Вестник Европы» в отделе редких книг почти все имеют переплет. Переплетные крышки оклеены «мраморной» бумагой или коленкором. 29 экземпляров выделяются из общей массы характерным суперэкслибрисом - тиснение золотом инициалов «BRT» на верхней крышке переплета. Примечательным элементом, позволяющим идентифицировать периодические издания, является технический ярлык на корешке журнала. Он представляет собой белую бумажную наклейку, на которой в двойной синей рамке написаны начальные буквы названия журнала, год и номер.

Самым популярным журналом в читательской среде был «Исторический вестник». Периодическое издание было основано в 1880 г., и к 1914 г. журнал уже насчитывал 13000 подписчиков, среди которых значилась и Тургеневская библиотека. На форзаце декабрьского номера журнала за 1910 г. сохранился шрифтовой экслибрис библиотеки.

«Толстый» журнал «Отечественные записки» начал поступать в Тургеневскую библиотеку с первых лет ее существования. Сотрудники библиотеки старались пополнить фонд недостающими, ранее изданными номерами этого журнала. Для многих экземпляров «Отечественных записок» был заказан переплет с суперэкслибрисом на верхней крышке переплета: «BIBLIOTHĖQUE RUSSE TOURGUENEV». В качестве покрывного переплетного материала использовалась ярко-синяя бумага, выделяющая эти экземпляры среди других периодических изданий. 


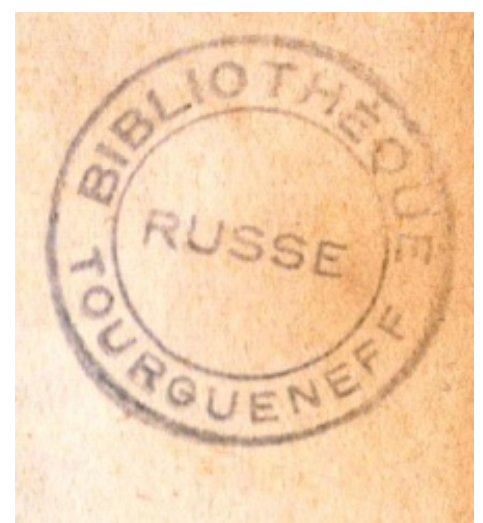

Владельческий штемпель 3

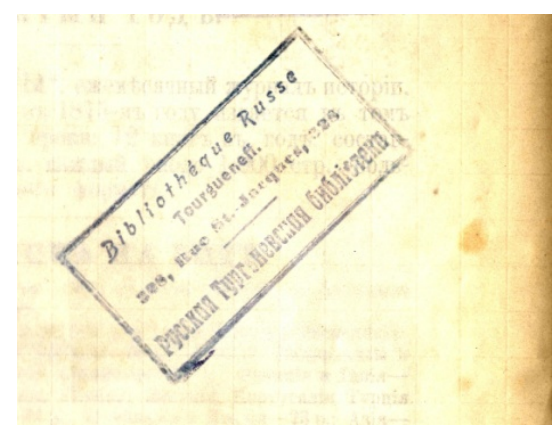

Владельческий штемпель 4

\section{Blbliathéque Rused Tourstuensศ. 9, Rue du Val do Grâce, 9

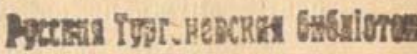

Владельческий штемпель 5

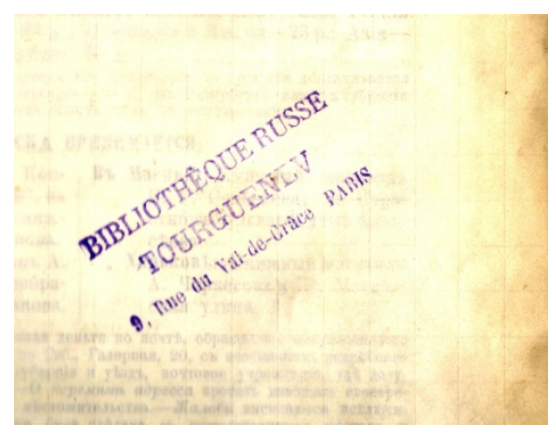

Владельческий штемпель 6

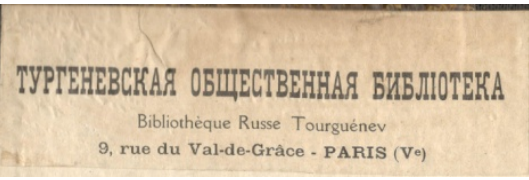

Экслибрис
В журнальном фонде Тургеневской библиотеки определенную нишу занимало периодическое издание по истории освободительного движения в России - ежемесячный журнал «Былое». 14 экземпляров этого издания хранятся теперь в отделе редких книг АКУНБ и востребованы в настоящее время читателями.

Судя по владельческим книжным знакам, проставленным на страницах периодических изданий, 16 \% из 192 выявленных журналов принадлежало ранее иным библиотекам и объединениям.

В фонд Тургеневской библиотеки издания поступали в разное время. Среди прежних владельцев можно отметить: Общество русских студентов в Париже (SOCIÉTÉ DES ÉTUDIANTS RUSSES PARIS), библиотеку и архив РСДРП (Россійская соціальдемократическая Рабочая Партія. Библіотека и архивъ.), библиотеку Лаврова-Гоца (BIBLIOTHÈQUE RUSSE PARIS LAVROFF-GOTZ), Русскую высшую школу общественных наук ( $\mathrm{R}$ des Hautes Etudes Sociales).

Особенно ценным пополнением явился дар из библиотеки Лаврова-Гоца. Он включал более 1700 книг, 32 годовых комплекта русских журналов за 1875-1916 гг. Петр Лаврович Лавров (1823-1900) -русский социолог, философ, публицист, один из идеологов народничества, издавал в Цюрихе и Лондоне журнал «Вперед». С 1877 г. Петр Лаврович проживал в Париже постоянно и являлся читателем Тургеневской библиотеки. В 1910 г. после смерти П. Л. Лаврова Русская общественная библиотека переехала на его квартиру на улице Святого Якова (rue St.-Jacques, 328) [3, c. 92].

В отделе редких книг выявлены два номера журнала «Вестник Европы» - № 4 за 1905 г. и № 11 за 1915 г. с владельческим знаком библиотеки Лаврова-Готц.

Изначально коллекция складывалась как личная библиотека П. Л. Лаврова, которая впоследствии пополнилась некоторыми русскими книгами, принадлежавшими Карлу Марксу. Позже библиотека была дополнена коллекцией Михаила Рафаиловича Гоца (1866-1906) - одного из организаторов Партии социалистов-революционеров (эсеров) [4, с. 283]. Возможно, передаче книжной коллекции Лаврова-Гоца в фонд Тургеневской библиотеки поспособствовал А. И. Рубанович (1859-1922), который состоял в Партии эсеров и активно занимался политической деятельностью. В 1883 г. он работал библиотекарем в Тургеневской библиотеке, и именно по его инициативе Русская общественная библиотека получила имя знаменитого русского писателя [5, c. 55].

При просмотре de viso выявленных периодических изданий с книжными знаками Тургеневской библиотеки особое внимание привлекает владельческий штемпель, проставленный на 23-х экземплярах журналов «Вестник Европы» и «Отечественные записки». Это овальный шрифтовой штемпель синего и красного цветов с надписью в рамке с зубчатым краем: «Россійская соціальдемократическая Рабочая Партія. Библіотека и архивъ».

Библиотека и архив Российской социал-демократической

рабочей партии были созданы в Женеве в январе 1904 г. группой большевиков-эмигрантов по поста- 


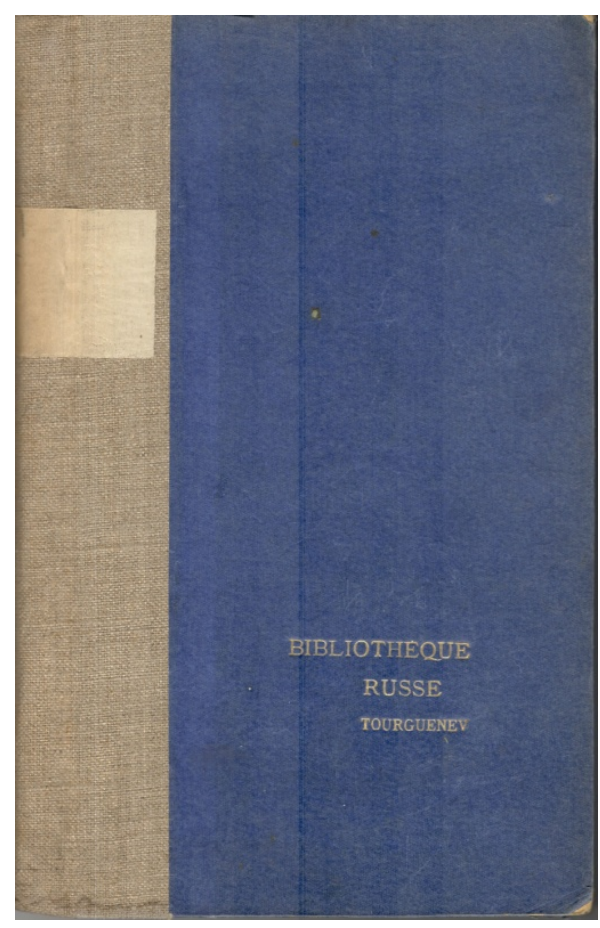

Суперэкслибрис 2

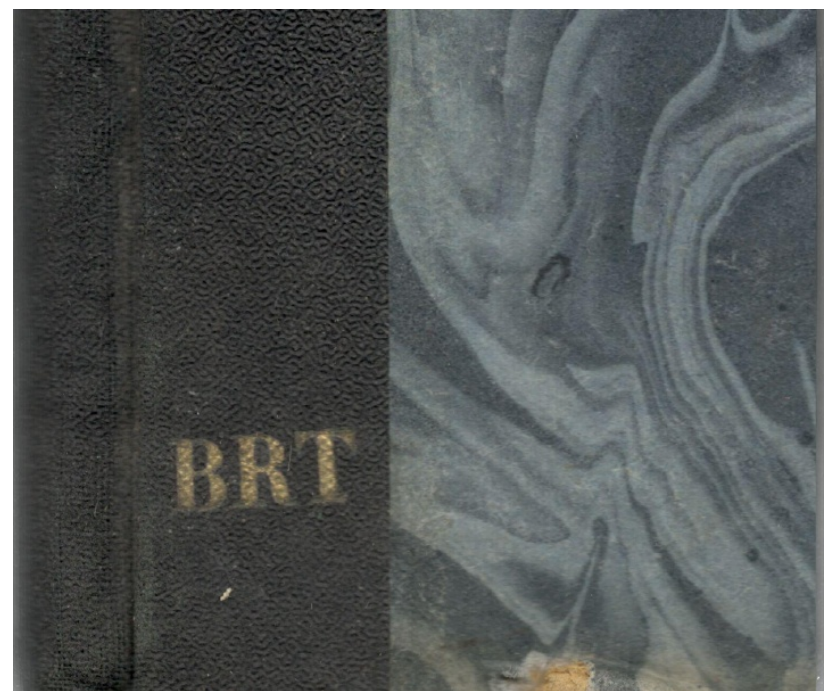

Суперэкслибрис новлению ЦК РСДРП при содействии В. И. Ленина. Для Женевской библиотеки выписывалось 118 названий журналов и газет на 16 языках. В ее фонд поступали материалы партийных съездов и конференций, рукописи, переписка партийных деятелей. В 1905 г. перед отъездом в Россию Ленин передал сюда свой личный архив и библиотеку. Деятельное участие в комплектовании фонда Женевской библиотеки принял Г. А. Куклин, библиофил и издатель, пожертвовав свои издания, дублетные экземпляры книг и журналов из личной коллекции.

Во время Первой русской революции в связи с массовым возвращением в Россию политэмигрантов необходимость в Женевской библиотеке и архиве РСДРП отпала. В январе 1906 г. собрание было расформировано и библиотека прекратила своё существование. Часть книг и документов была отправлена в Стокгольм, где хранилась в Народном доме до 1912 г., дальнейшая ее судьба неизвестна. Другая часть была отдана на хранение Г. А. Куклину, соединившему свою библиотеку-читальню с этими материалами. В 1907 г. по его завещанию библиотека перешла в собственность РСДРП и функционировала в Женеве до 1917 г. [6, c. 322]. Годами ранее, в 1910 г., руководитель библиотеки В.А. Карпинский отправил часть Женевской библиотеки и архива РСДРП в Париж, где собрание хранилось в запечатанном виде в Тургеневской общественной библиотеке. В 1923-1924 гг. значительная часть этих фондов была доставлена Испартом (Комиссией по истории Октябрьской революции) в Москву. Часть коллекции периодических изданий из собрания РСДРП влилась в фонд Тургеневской библиотеки. Накануне Первой мировой войны, с 5 января 1914 г. библиотека продолжила свою деятельность в новом помещении по адресу: улица Валь-де-Грас, 9 (rue du Val-de- Grâce, 9).

В газете «Парижский вестник» за 1914 г. были опубликованы сообщения о текущей работе библиотеки и ее перспективных планах, помещен отчет библиотеки за 1913 г. В числе положительных фактов отмечено значительное увеличение площади арендуемого помещения по сравнению с предыдущим. «Библиотека занимает теперь 5 комнат, где она может разместить свои книжные богатства. Библиотека имеет свой особый ход на улицу, что очень важно в смысле её самостоятельности и изолированности. Располагая свободным местом, библиотека сможет более тщательно и систематично регистрировать книжное имущество, составит карточный каталог и, наконец, напечатает свой каталог» $[7$, с. 5].

На начало 1914 г. фонд Русской общественной библиотеки составил 11850 томов книг. Наибольшим спросом среди читателей пользовались беллетристика на русском языке, журналы, книги по искусству, истории литературы, естествознанию. Среди подписчиков библиотеки стали появляться французы. Малоимущие читатели по особому постановлению Правления пользовались правом бесплатного чтения. Актуальной проблемой для библиотеки по-прежнему остается обеспечение 
сохранности фонда и его учет. В течение 1913 г. 22 подписчика из 233 не возвратили в библиотеку книги. Среди не сданных вовремя печатных изданий оказались и кропотливо составленные сотрудниками каталоги. Ценность их была настолько велика, что Правление библиотеки со страниц «Парижского вестника» обратилось к читателям с просьбой вернуть пропавшие каталоги: каталог по естествознанию, инвентарный каталог по истории литературы.

В годы Первой мировой войны Тургеневская библиотека обслуживала солдат из Русского экспедиционного корпуса, который, следуя союзническому долгу, сражался на фронтах Франции и проявил лучшие боевые качества. Некоторые из солдат и офицеров стали читателями библиотеки. За небольшой залог (3 франка) они имели возможность заказывать книги почтой. Многие военные, получившие ранения, после выписки из госпиталей направлялись в Ниццу на поправку.

Красивый средиземноморский город с мягким климатом стал набирать популярность среди русских аристократов с середины XIX в. Постепенно побережье Лазурного берега застраивалось особняками, появилось такое понятие как «русская Ницца». Гостеприимно распахнул свои двери для соотечественников и отель-пансионат «Родной угол». Хозяйкой пансионата была Мария Михайловна Соболева, образованная женщина, занимавшаяся переводами с иностранных языков. Для газеты «Русские вести», которая издавалась в Ницце в 1917-1918 гг., она переводила новости из иностранных газет. К услугам посетителей отеля, кроме великолепной кухни, предлагалась хорошо подобранная русская библиотека. В составе библиотеки имелось первое посмертное издание произведений А. С. Пушкина, вышедшее в 1838-1841 гг. Это издание было осуществлено за казенный счет по повелению императора Николая І в пользу наследников поэта и включало лишь те произведения, которые были опубликованы при его жизни.

В отделе редких книг АКУНБ был выявлен 2 том данного издания, с сохранившимся владельческим штемпелем с указанием адреса отеля-пансионата «Родной угол».

Следующим владельцем томика А. С. Пушкина в полукожаном переплете стала Русская общественная библиотека им. И. С. Тургенева. Шрифтовой штемпель проставлен на авантитуле и нахзаце. Судя по владельческому знаку, издание поступило в фонд библиотеки не ранее 1914 г., пополнив отдел беллетристики - самый популярный отдел среди читателей.

В период с 1914 по 1937 гг. на полках библиотеки обосновались сочинения и других русских литераторов: третий том Полного собрания сочинений В. А. Жуковского 1902 г., четвертый том Собрания стихотворений В. А. Жуковского 1821-1831 гг., вышедший в свет в 1849 г. при жизни автора, Полное собрание сочинений В. А. Слепцова 1903 г., первый том Сочинений А. М. Скабичевского 1890 г.

Теперь эти печатные издания с атрибутированными книжными знаками занимают достойное место в отделе редких книг Алтайской краевой библиотеки.

К началу Второй мировой войны Тургеневская библиотека превратилась в крупный культурный центр русского зарубежья, стала важной составной частью русской эмигрантской книжной культуры во Франции. В ее стенах читались публичные лекции, проводились выставки, устраивались концерты и новогодние ёлки для детей. Престиж библиотеки и фонды настолько выросли, что парижский муниципалитет предоставил ей помещение в историческом здании на улице Бюшери (rue de la Bûcherie, 13), где когда-то располагалась медицинская школа Парижского университета.

Помимо обширных комнат, в которых в 1937 г. библиотека разместила свой стотысячный фонд, она получила в свое распоряжение и вместительный зал на двести человек. В следующим году при библиотеке был организован «Русский литературный архив», в который принимались на хранение дневники, письма, рукописи и другие материалы личного и общественного характера. И. А. Бунин один из первых передал в новый отдел свой личный архив. Но настоящего развития это начинание не получило, всему помешала война. Деятельность библиотеки по приказу нацистского идеолога А. Розенберга была прекращена после занятия немцами Парижа в октябре 1940 г. Книги были упакованы в ящики и вывезены в неизвестном направлении. Долгое время считалось, что ценное собрание погибло в окрестностях Берлина.

Благодаря разысканиям американского историка-архивиста Патриции Гримстед Кеннеди удалось пролить свет на военную историю Тургеневской библиотеки. Оперативный штаб А. Розенберга, учитывая уникальность библиотеки и богатство эмигрантской литературы, решил на ее базе создать 
Восточную библиотеку для нужд нацистской пропаганды. Так Тургеневская библиотека оказалась в Берлине. В столицу были также свезены награбленные нацистами книжные коллекции с оккупированной территории СССР. После того как союзники начали стратегическую кампанию бомбардировок Берлина, Восточная библиотека была перевезена в относительно спокойный город Ратибор в Силезии (ныне польский город Рацибуж).

Большая часть Тургеневской библиотеки и книжные собрания шести советских библиотек были обнаружены весной 1945 г. трофейной бригадой 4-го Украинского фронта на территории Польши, в Мысловице (в семидесяти пяти километрах от Ратибора). В конце 1945 г. около 60000 книг со штампами Тургеневской библиотеки были перевезены из Мысловице в Дом офицеров Красной армии в городе Лигниц (ныне польский город Легница). Среди перемещенных изданий оказался второй том сочинений А. С. Пушкина, к которому в недавнем прошлом обращались посетители пансиона «Родной угол» и читатели Тургеневской библиотеки. Круглый штемпель, принадлежащий войсковой части с указанием полевой почты (02961-Д), проставлен на титульном листе книги и позволяет дополнить новыми сведениями историю бытования экземпляра.

Под инвентарным номером 160 был записан в фонд библиотеки Дома офицеров 3 том Полного собрания сочинений В. А. Жуковского, вышедший в 1902 г. Рядом на полке разместился 4 том стихотворений русского поэта 1849 г., получивший инвентарный номер 162. Скорей всего, книги с произведениями В. А. Жуковского не успели побывать в руках читателей, их ожидало следующее перемещение в белорусский военный городок Печи. С апреля 1947 г. там дислоцировалась 6-я гвардейская стрелковая Ровенская Краснознаменная дивизия. Владельческий знак библиотеки гарнизонного Дома офицеров городка Печи проставлен на обоих экземплярах.

В 1951 г. небольшая партия книг в количестве 362 томов была отправлена из военной базы в Печи в Государственную библиотеку им. В. И. Ленина (далее - ГБЛ). Возможно, среди отправленных изданий находились и эти два тома сочинений В. А. Жуковского. ГБЛ получала книги Тургеневской библиотеки на протяжении 1946-1948 гг. из четырех военных источников. Многие из поступивших книг были дублетными экземплярами уже имеющихся изданий, поэтому их использовали для обмена с другими библиотеками как внутри СССР, так и за рубежом. Алтайская краевая библиотека получила пять книг, переживших военное лихолетье и несколько территориальных перемещений, из Государственного книжного фонда в 1956 г.

После окончания войны группа энтузиастов-русских эмигрантов во главе с Т. А. Осоргиной, историком и библиографом, начала восстановление знаменитой Тургеневской библиотеки. Богатейший фонд был утрачен, и, чтобы возобновить работу библиотеки, пришлось формировать новый. Муниципалитет Парижа активно поддержал идею возрождения русской библиотеки и оказал материальную поддержку. После долгого перерыва, в 1959 г., возрожденная библиотека наконец была открыта. В настоящее время фонд ее составляет 50000 книг и журналов.

Историческая роль Русской общественной библиотеки имени И. С. Тургенева бесценна. Библиотека объединила несколько поколений людей, оказавшихся волею судеб вдали от России. На протяжении многих лет своего существования она была крупнейшим центром сохранения русской культуры и живого русского слова, местом культурного тепла для разных поколений эмигрантов. Книжные богатства библиотеки оказались связующим звеном русской диаспоры в духовном общении с Родиной, способствовали сохранению национального самосознания и исторической памяти.

Уцелевшие печатные издания в процессе одиссеи Тургеневской библиотеки из Парижа являются живыми свидетелями мировой истории, частью русской книжной культуры. Изучение выявленных в фонде АКУНБ экземпляров книг и журналов с владельческими знаками Тургеневской библиотеки позволит ввести в научный оборот общекультурный и исторический материал для работы по реконструкции книжного собрания Русской общественной библиотеки им. И. С. Тургенева.

\section{Список литературы}

1. Гинтовт-Дзевалтовский, В. Парижские встречи // Сибирские огни. - 1927. - № 2. - С. $78-127$.

2. Фирсов, Г. Г. Тургеневская общественная библиотека в Париже // Книга: исследования и материалы. Москва : Книга, 1986. - Сб. 53. - С. 129-143. 
3. Делевский, Ю. Тургеневская библиотека в Париже // Временник Общества друзей русской книги. Репр. изд. 1925 г. - Москва : Собрание, 2007. - С. 92-94.

4. Шишко, Л. Э. М. Р. Гоц // Былое. - 1906. - № 11. - С. 283-292.

5. Русская общественная библиотека им. И. С. Тургенева - перекресток духовной жизни России и Франции. - Санкт-Петербург : З Знаменитые универсанты СПбГУ, 2014. $-155 \quad$ c. - URL: https://www.academia.edu/33751447/M (дата обращения: 11.06.2020).

6. Бонч-Бруевич, В. Д. Библиотека и архив РСДРП в Женеве // Избранные сочинения : [в 3 т.] / В. Д. БончБруевич - Т. 2 : Статьи. Воспоминания. Письма, 1895-1914 гг. - Москва : Изд-во Акад. наук СССР, 1961.C. 307-322.

7. Н. П. Юбилей Тургеневской библиотеки // Последние новости. $-1925 .-24$ нояб. - URL : http://elib.shpl.ru/ru/nodes/9980-1647-1745\#mode/inspect/page/315/zoom/8 (дата обращения: 09.06.2020).

Olga $A$. Trukhina

Shishkov Altai Regional Universal Scientific Library (Barnaul, Russia) ork_akunb@mail.ru

\title{
THE ODDITY OF THE RUSSIAN TURGENEV LIBRARY (PARIS, FRANCE)
}

\begin{abstract}
The paper briefly describes a history of establishing Russian Public Library in Paris, 1875, by an initiative of Russian politician German Lopatin; now, the Library is considered as the oldest Russianlanguage book collection formed outside Russia. Ivan Turgenev's personal library took as a basis of the memorial document collection that gradually became a center of cultural life for the first wave of Russian revolution emigration to France. The article discloses content of the document collection by type of issues, calls its sources until it was seized by Nazi occupational administration in 1940, outlines the history of its "travelling". Also, the general description of several examples of books and magazines that previously belonged to Ivan Turgenev's Russian Public Library and now is stocked in Vyacheslav Shishkov Altai Regional Universal Scientific Library (Barnaul, Russia) is given.

Keywords: Ivan Turgenev Russian Public Library, Turgenev Library, ex-libris (book marks), Turgenev Library book collection, library and Archives of Russian Social Democratic Labour Party, Lavrov-Gotz's library, Vyacheslav Shishkov Altai Regional Universal Scientific Library.
\end{abstract}

